\title{
8
}
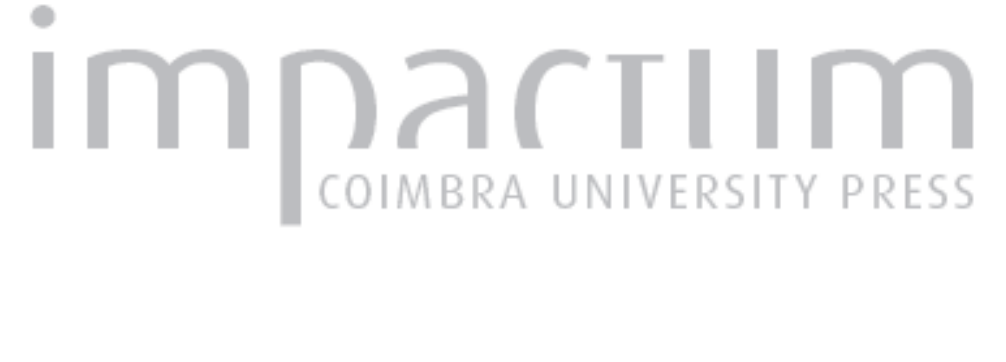

\section{As relações entre "fins" e meios" e a relevância moral da Phronesis na ética de Aristóteles}

\section{Autor(es): $\quad$ Angioni, Lucas}

Publicado por: Faculdade de Letras da Universidade de Coimbra, Instituto de Estudos

URL

persistente: Filosóficos

DOI:

URI:http://hdl.handle.net/10316.2/33373

DOI:http://dx.doi.org/10.14195/0872-0851_35_6

\section{Accessed : $\quad$ 26-Apr-2023 06:28:01}

A navegação consulta e descarregamento dos títulos inseridos nas Bibliotecas Digitais UC Digitalis, UC Pombalina e UC Impactum, pressupõem a aceitação plena e sem reservas dos Termos e Condições de Uso destas Bibliotecas Digitais, disponíveis em https://digitalis.uc.pt/pt-pt/termos.

Conforme exposto nos referidos Termos e Condições de Uso, o descarregamento de títulos de acesso restrito requer uma licença válida de autorização devendo o utilizador aceder ao(s) documento(s) a partir de um endereço de IP da instituição detentora da supramencionada licença.

Ao utilizador é apenas permitido o descarregamento para uso pessoal, pelo que o emprego do(s) título(s) descarregado(s) para outro fim, designadamente comercial, carece de autorização do respetivo autor ou editor da obra.

Na medida em que todas as obras da UC Digitalis se encontram protegidas pelo Código do Direito de Autor e Direitos Conexos e demais legislação aplicável, toda a cópia, parcial ou total, deste documento, nos casos em que é legalmente admitida, deverá conter ou fazer-se acompanhar por este aviso. 


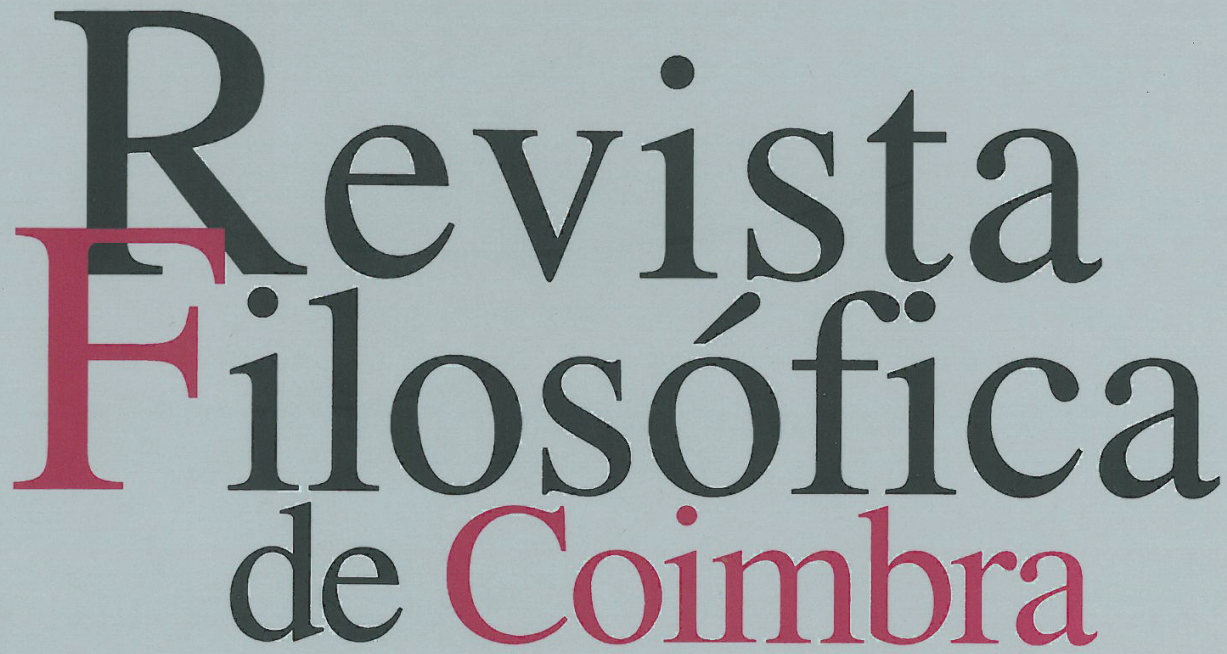

vol.18|n. $.35 \mid 2009$

João Maria André

Mário Santiago de Carvalho

Filipa Medeiros

Edmundo Balsemão Pires

Luís António Umbelino

Luís M. Augusto

Lucas Angioni 


\title{
AS RELAÇÕES ENTRE “FINS” E "MEIOS” E A RELEVÂNCIA MORAL DA PHRONESIS NA ÉTICA DE ARISTÓTELES
}

\author{
LUCAS ANGIONI
}

Universidade de Campinas, Brasil

\begin{abstract}
Resumo: Neste artigo, discuto três tipos de relação entre meios e fins na ética aristotélica, tendo por objetivo esclarecer qual é a divisão do trabalho entre virtude moral e phronesis na adoção de fins e na determinação de meios para as ações virtuosas. A phronesis parece ter como encargo principal determinar os meios, embora envolva certa compreensão dos fins. No entanto, a phronesis não pode ser parasitária da virtude moral na compreensão dos fins, pois, caso contrário, dificilmente poderia ter valor moral intrínseco. Meu objetivo é mostrar que, de acordo com certo tipo de relação entre meios e fins, o valor moral intrínseco da phronesis pode ser mais bem esclarecido.
\end{abstract}

Abstract: I discuss three kinds of relationships between ends and means in the Aristotelian ethical theory, in order to clarify how moral virtues and phronesis are related both in adopting ends and in determining means for virtuous actions. Phronesis seems to be mainly charged with determining means for an end given by the moral virtues, but it has to involve some conception of ends too. But phronesis cannot be parasitic on moral virtue concerning the conception of ends, for otherwise it will lack intrinsic moral value. I argue that the intrinsic moral value of phronesis can be better understood through a certain kind of relation between means and ends that has not received scholars' attention.

Palavras-chave: Sabedoria prática, Teoria da ação, Psicologia da ação, Moralidade, Prudência, Teleologia.

Qual é a relação entre meios e fins na teoria moral de Aristóteles? É claro que, antes de tentar responder a pergunta, devemos esclarecer como seus termos devem ser entendidos. Usamos o termo "meio", neste artigo, apenas como expediente para introduzir aquilo que, no jargão 
aristotélico, é designado pela descrição "ta pros ta tele" (ou expressões ligeiramente diversas, mas equivalentes), ao passo que o termo "fim" é usado para introduzir aquilo que Aristóteles designa pelos termos "telos" e "skopos", e que se refere ao objetivo que determinado agente, concebendo-o como um bem, fixa como meta a ser realizada pela sua ação.

Uma das maiores dificuldades para compreender as relações entre meios e fins consiste na tese, aparentemente defendida por Aristóteles em EN III, de que a prohairesis e a deliberação têm por objeto as coisas que promovem o fim ( $t a$ pros ta tele), ou exclusivamente, ou preponderantemente $^{1}$. Não poderia o agente deliberar sobre os fins que adotará para suas ações? Não pretendo abordar o problema por esse ângulo, porém. Quero dizer que meu problema principal não consiste em saber se Aristótels admite de algum modo deliberação e escolha dos fins. Meu foco consiste antes em analisar a divisão do trabalho entre, de um lado, as virtudes morais e, de outro, a phronesis, na adoção e apreciação de fins e meios ${ }^{2}$. Se a prohairesis diz respeito a meios, ta pros ta tele (1111b 26-27), ou exclusivamente ou preponderantemente; e se a virtude moral é uma hexis prohairetike (1106b 36); seria de se esperar a conclusão de que a virtude moral é uma hexis que lida, preponderante ou exclusivamente, com meios (de preferência a fins). No entanto, Aristóteles parece dizer que a virtude responde pela correção dos fins, ao passo que a phronesis (que não é uma hexis prohairetike) diz respeito à correção das coisas pros ta tele (1144a 7-9, 1145a 5-6). Há vários modos de resolver essa aparente inconsistência ${ }^{3}$. Meu objetivo consiste em resolvê-la pela análise da noção de ta pros ta tele, ou melhor, pela análise das relações entre fins e meios (ta pros ta tele).

${ }^{1}$ Cf. EN 1111b 26-29, 1112b 11-6, 1113a 12-14, EE 1127b 25-29.

2 Por adoção entendo o processo pelo qual o desejo toma como objeto algo a ser realizado. Por apreciação entendo o processo pelo qual o raciocínio (logos) considera e avalia os argumentos que justificariam a adoção de certo objeto pelo desejo. É claro que, uma vez adotado e apreciado um fim, os mesmos procedimentos aplicam-se, transitivamente, aos meios. Essas elucidações já indicam que, no meu entender, pode-se deliberar sobre fins, sob certas condições, ao menos se um processo de apreciação de fins puder ser entendido como deliberação. Mas esse não é o meu ponto, nem meu interesse principal neste artigo.

${ }^{3}$ Como já antecipo, a inconsistência não é senão aparente, mas nem por isso o leitor de Aristóteles deixa de experimentar certo desconforto. Ver Kenny 1979, p. 103. 
II.

Há três tipos possíveis de relação entre fins (tele) e coisas relativas ao fim (ta pros ta tele). Meu propósito não consiste em argumentar que a prohairesis e a deliberação tomam exclusivamente apenas um desses tipos. Dependendo da situação, prohairesis e deliberação podem lidar com qualquer um desses três tipos. Meu propósito consiste em argumentar que, dessas três relações possíveis, há uma que talvez seja mais relevante ou, ao menos, a mais esclarecedora para destacar a relevância moral da escolha deliberada e da phronesis, na determinação dos "meios".

Dois tipos de relação entre fins (tele) e coisas relativas ao fim (ta pros ta tele) são contemplados respectivamente por aquilo que a tradição mais recente denominou de meios instrumentais e meios constitutivos ${ }^{4}$. Pretendo acrescentar um terceiro tipo ${ }^{5}$.

1) o primeiro tipo de relação entre fins (tele) e coisas relativas ao fim (ta pros ta tele) consiste em relação meramente instrumental, em que as coisas relativas ao fim são, em si mesmas, neutras do ponto de vista moral e contam como instrumentos eficazes para a realização de um fim. Para melhor diferenciar esse primeiro tipo do segundo, que introduzirei logo mais, é preciso acrescentar que, nesse primeiro tipo de relação, as coisas relativas ao fim não são constitutivas ou constituintes do fim: elas sãteo apenas etapas, ou realizam etapas, que contribuem para a realização do fim, mas, uma vez realizado o fim, não é relevante se o agente ainda persiste a realizá-las ou não.

Assim, este primeiro tipo de relação entre meios e fins poderia ser definido do seguinte modo:

Definição (1): $m$ é um meio para a realização do fim $F$ se e somente se são satisfeitas conjuntamente as seguintes condições: (i) $m$ consiste em algo que contribui ${ }^{6}$ para a realização do fim $F$, (ii) $m$ não é capaz de produzir por si mesmo, isoladamente, o fim $F$ (outros meios devem ser acrescentados), (iii) a realização ou o uso (enfim, a energeia) de $m$ se dá em um instante distinto (anterior a) do instante em que o fim $F$ se realiza por completo.

\footnotetext{
${ }^{4}$ Ver Irwin, 1999, p. 205. Para longa discussão, ver Kraut, 1989, p. 13, 210-217.

${ }^{5}$ Ignoro se esse terceiro tipo já foi apresentado na literatura secundária, mas parece-me que ele não recebeu o devido destaque que merece. De todo modo, não almejo nenhum ineditismo no meu ponto.

${ }^{6}$ O sentido de "contribuir", nesta cláusula, poderá ser mais bem compreendido por comparação com a cláusula (i) da terceira definição, que será introduzida logo mais.
} 
Seja-nos permitido usar exemplos bem latos para esclarecer esse primeiro tipo de relação entre fins (tele) e coisas relativas ao fim (ta pros ta tele). $\mathrm{O}$ próprio Aristóteles usa freqüentemente exemplos da medicina (ou de outras artes ou ciências produtivas) para esclarecer o conceito de deliberação, senão também o de prohairesis ${ }^{7}$.

Assim, para o médico, que supõe como fim a ser realizado o restabelecimento da saúde de certo paciente, contam como meios, coisas relativas ao fim (ta pros ta tele), coisas tão díspares como operações e instrumentos. Suponha-se que, em dada circunstância, a cura dependa de que o médico realize uma incisão com o bisturi no braço do paciente etc. Contam como "meios" para o fim do médico não apenas a incisão, que é uma operação realizada pelo médico de acordo com sua ciência, mas também o bisturi, que é um mero instrumento pelo qual se realiza a incisão. Tanto o bisturi como a incisão satisfazem os três critérios acima arrolados ${ }^{8}$.

Outro exemplo talvez seja mais eficaz: o construtor de uma casa. O fim do construtor é produzir uma edificação que satisfaça as propriedades relevantes pelas quais se define uma casa, isto é, uma edificação que sirva de abrigo para pessoas e bens, contra chuva, vento, ladrões, etc. ${ }^{9}$ Tendo em vista esse fim, o construtor determina, por um raciocínio deliberativo, quais são as coisas que ele deve realizar para produzir tal edificação. Assim, o construtor determina que ele deve, por exemplo, produzir alicerces (feitos de pedra), produzir paredes (de pedras ou outro material), produzir um teto (com caibros de madeira). Ora, produzir alicerces, por exemplo, satisfaz as três condições acima arroladas.

Não afeta o meu ponto objetar que esse raciocínio do construtor não é reconhecido por Aristóteles como um autêntico caso de deliberação ${ }^{10}$. Há controvérsias a esse respeito, e não vou analisá-las neste momento.

${ }^{7}$ Cf. EE 1226a 34-35, 1227a 19-20, EN 1112b 12-20; 1141b 18-21; Metafísica 1032b 6-10, 17-21, Física 200b 2-3.

8 Talvez apenas um caso não seja evidente por si e requeira argumentação. Alguém poderia perguntar se a incisão de fato satisfaz o critério (ii). O que quero dizer pode ser mais bem ilustrado se levarmos em conta, em nosso exemplo, que a incisão requer alguns procedimentos: procedimentos anteriores, de preparação, bem como procedimentos posteriores. Por exemplo, desinfetar o bisturi, bem como desinfetar a pele no corpo do paciente, etc. Ou então, segurar uma compressa contra a incisão após alguns segundos etc. Pouco importa a precisão médica desses exemplos. O que quero ilustrar é o seguinte. Sem os procedimentos preparatórios ou pós-operatórios, a incisão poderia causar infecção, em vez de saúde.

${ }^{9}$ Cf. De anima 403b 4-6, Metafísica 1043a 32.

${ }^{10}$ Em Física 199b 28, Aristóteles afirma que a técnica não delibera. Essa afirmação deve ser entendida em seu contexto. Ver meus comentários em Angioni, 2009. 
Pois basta-me argumentar que há uma analogia entre esse caso do construtor e certos casos de deliberação moral em sentido estrito. Ao elucidar o conceito de deliberação, Aristóteles freqüentemente usa exemplos que satisfazem as características daquilo que ele chama, em Física II 9, de "necessidade sob hipótese". Dado um fim supostamente assumido pelo agente ou pelo produtor (representado na premissa menor de um silogismo de primeira figura), e dadas certas exigências necessárias para a realização desse fim (representadas na premissa maior), segue-se que o agente ou produtor que quer realizar tal fim deve querer realizar aquilo que conta como exigência necessária para a realização desse fim (consequiência que é representada na conclusão).

Passo a caracterizar brevemente o que considero ser o segundo tipo de relação entre fins (tele) e coisas relativas ao fim (ta pros ta tele). $\mathrm{O}$ segundo tipo de relação entre fins (tele) e coisas relativas ao fim (ta pros ta tele) consiste em relação de constituição, em que as coisas relativas ao fim são, em si mesmas, partes integrantes do fim. Esse segundo tipo de relação compartilha com o primeiro algumas características, como veremos, mas difere do primeiro pelo fato de que as coisas relativas ao fim são constitutivas do fim e, por essa razão, não são em si mesmas moralmente neutras.

Assim, poderíamos definir esse segundo tipo de relação entre meios e fins do seguinte modo:

Definição (2): $m$ é um meio para a realização do fim $F$ se e somente se são satisfeitas conjuntamente as seguintes condições: (i) $m$ consiste em algo que contribui para a realização do fim $F$, a título de parte constitutiva do fim $F$; (ii) $m$ não é capaz de produzir por si mesmo, isoladamente, o fim $F$ (dado que $m$ é apenas parte de $F$ ), (iii) a realização (enfim, a energeia) de $m$ pode dar-se em um instante anterior ao instante em que o fim $F$ se realiza por completo, mas a realização de $m$ preserva-se simultaneamente à realização do fim $F$.

Para exemplificar esse tipo de relação entre fins (tele) e coisas relativas ao fim (ta pros ta tele), podemos tomar a relação entre, por exemplo, a saúde e a eudaimonia. Talvez esse exemplo seja controverso porque depende de como se entende a noção de eudaimonia (como bem dominante, ou bem inclusivo, ou ainda outra alternativa) ${ }^{11}$, mas, ao menos em nível bem geral, creio ser verdadeiro afirmar que essa relação satisfaz os nossos três critérios. De fato, a saúde contribui para a realização da

$11 \mathrm{O}$ exemplo depende também da interpretação do controverso passo em EN VI 13, 1144a 3-6. 
eudaimonia sendo uma parte dela (cf. 1144a 4-6) ${ }^{12}$; a saúde, no entanto, sendo apenas uma parte, não é suficiente para engendrar por si só a eudaimonia no agente saudável ${ }^{13}$; a atualização da saúde pode dar-se ao mesmo tempo que a eudaimonia. Por contraste, note-se que a realização da incisão médica não pode ocorrer ao mesmo tempo em que ocorre a saúde.

Podemos, no entanto, usar exemplo menos controverso. No caso da construção de uma casa, podemos tomar os alicerces de acordo com essa segunda relação entre fins (tele) e coisas relativas ao fim (ta pros ta tele). De fato, os alicerces (i) consistem em partes da casa, que contribuem para a realização da casa, (ii) não são suficientes para engendrar, por si mesmos, a realização plena da casa, (iii) encontram-se efetivamente realizados (energeiai) durante todo o tempo em que uma casa encontra-se atualmente realizada.

Os dois exemplos têm entre si uma assimetria, quanto ao critério (ii): é claro que os alicerces são, rigorosamente, condição necessária (mas não suficiente) para a realização da casa, ao passo que não é muito claro se a saúde seria, de fato, condição necessária para a realização da eudaimonia ${ }^{14}$. De todo modo, essa assimetria não interfere no meu ponto principal. Não quero apresentar uma tipologia exaustiva de relações entre fins (tele) e coisas relativas ao fim (ta pros ta tele). Quero apenas ressaltar certo tipo que, a meu ver, é o mais relevante e o mais esclarecedor para compreender as noções de prohairesis e deliberação, bem como as virtudes que lhes são associadas.

Passemos, então, ao terceiro tipo de relação entre fins (tele) e coisas relativas ao fim (ta pros ta tele). O terceiro tipo de relação entre fins (tele) e coisas relativas ao fim (ta pros ta tele) consiste em relação mais difícil de caracterizar do ponto de vista geral. Trata-se de uma relação na qual o fim é inevitavelmente indeterminado, em virtude da própria natureza

12 O passo 1144a 4-6 é bem controverso, mas entendo que "all' hôs hê hygieia" deve ser entendido como abreviação de "all' hôs hê hygieia poiei eudaimonian, houtôs kai hê sophia poiei eudaimonian", de modo que a cláusula explicativa que se segue aplica-se tão bem à sabedoria quanto à saúde: ambas são partes da "virtude do homem" no seu todo, sendo que "virtude total", neste contexto, deve ser entendida à luz da noção de "virtude do homem" em 1106a 22-24 e, no meu entender, coincide com a virtude pela qual o homem desempenha bem seu ergon (1098a 10-11, 15-17).

13 A saúde se conta entre os bens externos que fazem parte do "coro" de bens que acompanham a eudaimonia (cf. 1099a 24-29).

14 Pode-se argumentar que a saúde não é condição necessária para a eudaimonia porque, se fosse, não se poderia atribuir eudaimonia a um fulano que, tendo vivido sua vida inteira na mais perfeita eudaimonia, morre de câncer (por exemplo). 
das circunstâncias relevantes que o envolvem e que condicionam sua realização. É claro que não se trata de uma indeterminação total, mas relativa. O fim, neste caso, é algo suficientemente determinado para ser compreendido pelo agente como um fim, mas é caracterizado por uma descrição geral e vaga. Por exemplo: tome-se como fim o propósito de agir com temperança. Esse propósito é determinado o bastante no sentido de que o agente o compreende como algo distinto do propósito de agir de modo intemperante; mas tal propósito é vago e indeterminado, de modo que o agente que o acolhe fica, em cada circunstância singular relevante, diante da seguinte pergunta: em que consiste agir com temperança, neste caso em que me encontro presentemente? ${ }^{15}$

Em complementação, as coisas relativas ao fim, neste caso, consistem em especificações dessa descrição geral, de acordo com circunstâncias singulares. As coisas relativas ao fim são tais que fazem o fim passar da vagueza para a determinação completa, e são tais porque, neste caso, elas consistem em uma realização total do fim. Seria verdadeiro dizer que, neste terceiro tipo de relação, a realização do fim consiste na realização das coisas relativas ao fim (e vice-versa). A realização do fim não pode ser outra coisa senão, estritamente, a realização de certa coisa "relativa ao fim", sem exigir etapas complementares. Assim, as coisas relativas ao fim, neste caso, são suficientes para realizar, por sua própria realização, o fim. Ou melhor: a realização delas, em dada circunstância, consiste na própria realização do fim.

Assim, poderíamos definir este terceiro tipo de relação entre meios e fins do seguinte modo:

Definição (3): $m$ é um meio para a realização do fim $F$ se e somente se são satisfeitas conjuntamente as seguintes condições: (i) $m$ consiste em algo que realiza, por sua própria realização, o fim $F^{16}$; (ii) $m$ é capaz de produzir por si mesmo, isoladamente, o fim $F$ (dado que realizar $m$ consiste em realizar $F$ ), (iii) a realização (enfim, a energeia) de $m$ se dá simultaneamente à realização do fim $F^{17}$.

15 Essa situação, em que a vagueza dos parâmetros para a decisão moral se mostra insuficiente no confronto com a determinação plena das circunstâncias singulares, é claramente percebida como um problema por Aristóteles. Ver EN VI 1, 1038b 25-34, EN II 9, 1109a 24-30, 1109b 14-23.

${ }^{16}$ Compare-se essa condição com a condição (i) das outras definições, em que o meio $m$ foi definido como algo que apenas contribui parcialmente para a realização do fim.

${ }^{17}$ Não é possível conceber um instante $t$ em que a realização do meio $m$ seja o caso, mas a realização do fim $F$ não seja o caso, ou em que a realização do meio $m$ não seja o caso, mas a realização do fim $F$ seja o caso (compare-se com a relação entre a inicisão feita pelo médico e o restabelecimento da saúde). 
Esse terceiro tipo é o mais relevante para determinar, por exemplo, o papel da phronesis como complemento indissociável da virtude moral, bem como para determinar em que consiste a euboulia e a percepção que constituem a phronesis.

Mas, justamente para ressaltar esse ponto, voltemos aos dois outros modos de relação entre fins e coisas relativas ao fim, e tentemos analisar as relações entre phronesis e virtude moral segundo esses dois modos.

\section{III.}

De acordo com certos textos da Ethica Nicomachea (ao menos), é plausível atribuir à teoria moral de Aristóteles a seguinte divisão de responsabilidades. A virtude moral encarrega-se da correção do fim de uma ação, ao passo que a phronesis encarrega-se da correção (isto é, da eficácia) das coisas que promovem ou realizam o fim (1144a 7-9, 1145a 5-6). No entanto, a phronesis está longe de ser redutível à mera destreza (deinotes) instrumental no cálculo e na promoção dos meios que realizam um dado fim. A phronesis tem em si mesma um valor moral ${ }^{18}$. No entanto, parece que não seria verdadeiro atribuir a Aristóteles a tese de que o valor moral da phronesis seria totalmente derivado do valor moral dos fins assumidos pelo agente virtuoso, como se este agente já pudesse de antemão selecionar seus fins, moralmente corretos, independentemente da phronesis. Resta saber, assim, como a phronesis, sendo responsável pela determinação das coisas que promovem o fim (ta pros ta tele), comporta em si mesma um valor moral intrínseco. Em outras palavras, se a phronesis tem um valor moral intrínseco, é porque ela é algo mais que mera deinotes, bem como algo mais que mera habilidade no raciocínio deliberativo pelo qual se descobrem meios adequados para a realização de um fim. O valor moral intrínseo da phronesis exige que ela tenha alguma parte relevante na determinação dos fins assumidos pelo agente.

Assim, uma resposta óbvia para o problema que acabei de formular consiste em dizer que a phronesis seria responsável não apenas pela determinação das coisas que promovem o fim ( $t a$ pros ta tele), mas também pela determinação dos próprios fins. Essa resposta pode ser fundada de dois $\operatorname{modos}{ }^{19}$. Primeiro, pela alegação de que fins e meios são

${ }^{18}$ Cf. EN VI 13, 1044a 28-30, 1044b 30-32.

19 Não me parece razoável dizer que a phronesis compreende verdades sobre os fins, mas é a virtude natural ou a virtude propriamente dita que a habilita para tal compreensão (Reeve, 1992, p. 87). Ora, isso é muito vago e, em rigor, redunda na tese que há pouco rejeitei, a saber, a tese de que o valor moral da phronesis seria totalmente derivado do 
designações relativas: com exceção do fim último que é a eudaimonia, pode-se dizer que uma mesma coisa que, sob certo aspecto, é um fim, dotado de valor moral instrínseco, pode ser tomada como meio em relação a um fim ulterior (cf. 1097b 2-5). Nessa perspectiva, a phronesis, embora tenha por encargo determinar coisas relativas ao fim (meios), também teria papel relevante na determinação de um fim, na medida em que as coisas que são meios para um fim podem ser tomadas elas mesmas, sob outro aspecto, como fins. Segundo, pode-se alegar que Aristóteles concebe a phronesis como uma compreensão correta dos fins. Muitos alegam que Aristóteles afirma isso em $E N 1142$ b 33, e, em defesa dessa interpretação, recorrem a $E N$ VI 1: Aristóteles estaria a dizer que a phronesis (= orthos logos) seria uma correta compreensão do fim último ("skopos" em 1138b 22) das ações humanas.

Rejeitarei as duas estratégias de resposta às quais acabo de aludir. Não as discutirei em pormenor, pois julgo que a alternativa que apresentarei elucidará por si mesma algumas de minhas razões. No entanto, cabe discutir um pouco cada uma delas, e começo pela segunda. Ora, dizer que a phronesis é uma correta compreensão dos fins últimos funda-se em interpretação controversa do texto ${ }^{20}$. Mas sobretudo julgo ser questionável

valor moral dos fins assumidos pelo agente virtuoso, como se este agente já pudesse de antemão selecionar seus fins, moralmente corretos, independentemente da phronesis. Outra saída para o problema, a qual não discutirei aqui, é a de Cooper, 1999, p. 271: a phronesis, como virtude do intelecto prático, é a fonte que determina os fins para o desejo racional (boulesis), sendo as virtudes morais relativas aos fins concernentes aos desejos não-racionais.

${ }^{20}$ De fato, em 1142b 33, não é muito claro qual é o antecedente do pronome relativo "hou". Do ponto de vista sintático abstratamente considerado, sem atenção ao contexto, as opções seriam três: (i) o antecedente de "hou" seria "to telos", o fim, resultando na interpretação a que aludimos, que entende a phronesis como "compreensão correta do fim" (cf. Irwin, 1999, p. 249; Kraut, 1989, p.38, n. 22; Cooper, 1986, p. 101) ; (ii) o antecedente de "hou" seria "to sumpheron", o adequado, o conveniente, resultando em interpretação que transformaria a phronesis em mera destreza instrumental na compreensão eficaz dos meios; (iii) o antecedente de "hou" seria a inteira expressão "to sumpheron pros to telos", aquilo que é adequado para um dado fim. Esta última interpretação tem a seu favor razões filológicas e filosóficas. Do ponto de vista filosófico, é muito mais razoável compreender a phronesis como uma compreensão correta dos meios adequados para um dado fim moralmente bom, assumido pela virtude moral (cf. 1144a 6-9, 20-22), visto que Aristóteles insiste em ressaltar que a phronesis não se reduz à mera destreza (cf. 1144a 28-30), e visto que Aristóteles nada diz a respeito da suposta tarefa que a phronesis teria na concepção do fim (cf. Broadie, 2002, p. 376). Do ponto de vista filológico, argumentar em favor de (i) em razão da "maior proximidade" do antecedente do relativo é sinal de ignorância surpreendente, e argumentar em favor de (ii) ignora o fato de que "to sumpheron", tanto 
a proposta de interpretar "skopos" em EN VI 1, 1138b 22, como menção ao fim último ${ }^{21}$. Ora, não faz sentido exigir da phronesis uma compreensão conceitualmente mais apurada da noção de eudaimonia. O passo em $1138 \mathrm{~b}$ 21-25 deve ser interpretado de outra maneira, como tentarei mostrar.

À primeira vista, se poderia julgar que minha intepretação vai na direção da primeira estratégia há pouco mencionada. No entanto, julgo que a primeira estratégia é ainda vaga e pouco satisfatória, no sentido de que não é muito elucidativa a respeito de vários problemas da teoria moral de Aristóteles. Por sua vagueza, ela não elucida qual seria a distribuição de responsabilidades, ou a divisão do trabalho, entre a phronesis e a virtude moral. Dizer que a phronesis determina fins porque (a) ela determina coisas relativas ao fim (meios) e (b) estas coisas podem ser descritas, em outro contexto, sob a designação de "fim", é equivalente a dizer que o construtor constrói algo agradável, porque (a) ele constrói casas e (b) ocorre que a casa que ele constrói pode ser descrita, em outro contexto, como agradável. Não basta dizer que uma mesma coisa, por exemplo, a honra ou a virtude, pode ser tomada ora como fim em si mesmo, ora como meio para a promoção de um fim ulterior. Deve-se esclarecer de que modo, em cada uma dessas situações, a virtude moral do agente relaciona-se com o fim e as coisas que promovem o fim, e de que modo a phronesis relaciona-se com o fim e as coisas que promovem o fim. Assim como o agradável é construído pelo construtor, mas não qua construtor, mas kata sumbebekos, porque o construtor per se constrói algo, a casa, a que ocorre o atributo de ser agradável; do mesmo modo, um fim (a honra) pode ser apreciado e adotado pela phronesis, mas apenas kata sumbebekos, porque ocorre que a phronesis, qua phronesis, determina a honra como meio para um fim ulterior, mas a honra pode, em outro contexto, ser verdadeiramente descrita pela designação de "fim".

Passo a expor a resposta que proponho para o problema de saber como a phronesis pode ter papel relevante na determinação dos fins e, conseqüentemente, pode ter relevância moral intrínseca. Suponha-se,

em grego como no correlato que se propuser em português, é uma expressão incompleta: não faz sentido falar em "adequado" ou "conveniente", a não ser que se pressuponha e se queira dizer "adequado ou conveniente para tal coisa", isto é, para o fim, o que redunda na opção (iii). Pode-se, é claro, falar do "sumpheron" com abstração do fim para o qual ele é "sumpheron", não o nego: mas seria inverossímil que Aristóteles falasse abstratamente do "sumpheron" ao usar a expressão "to sumpheron pros to telos".

21 Discordo daqueles que tomam "skopos" em 1138b 22 como referência ao fim último. Ver Cooper, 1986, p. 102-3; Reeve, 1992, p. 168, diz que o skopos em questão é a eudaimonia ou, em Reeve, 2008, p. 102, a eupraxia. Kraut, 1989, p. 330, diz que o skopos deve ser uma ou a phronesis ou a sophia. 
então, um agente virtuoso, que adotou um fim moralmente correto para suas ações. Suponha-se, para exemplificação, que tal agente acolheu para si o fim de ser temperante no consumo de bebidas alcóolicas. É plausível encontrar, para a realização desse fim, um meio do primeiro tipo que propusemos, sobretudo no terreno da mera continência. Nosso agente pode ter propensão natural ao excesso e, para manter-se na mediedade que acolheu como fim, ele decide consumir regularmente certas pastilhas que inibem o desejo de beber. É claro que, entre o fim ser temperante no consumo de bebidas e o meio ingerir regularmente as pastilhas inibidoras, temos a primeira relação entre meios e fins. Mas o exemplo é ainda inadequado, visto que alguém que precisa de pastilhas inibidoras não é temperante, mas apenas continente. Suponha-se, então, um agente realmente temperante, que tem prazer ao preservar a mediedade no consumo de bebidas alcóolicas. De que modo a primeira relação entre meios e fins poderia ser exemplificada? Tomemos, por exemplo, certos movimentos corporais, como o de agarrar um copo de bebida e levá-lo à boca, ou o de aproximar-se das garrafas e copos, etc., ou os opostos, isto é, o não agarrar um copo, mas permanecer imóvel quando a bebida é oferecida, etc. É claro que, entre o entre o fim ser temperante no consumo de bebidas e o meio pegar (ou não pegar) o copo de bebida etc., temos a primeira relação, ou mesmo a segunda. De fato, pegar o copo (para beber a quantia moderada) contribui para a realização da temperança, mas não é suficiente por si só para a realização da temperança, por duas razões: (i) porque a efetiva realização da temperança depende dos fatores enunciados em 1105a 28-33, que versam sobre as disposições psicológicas do agente; (ii) porque a realização do movimento de pegar o copo obviamente não inclui a realização de todos os movimentos necessários para realizar o ato de beber. Por outro lado, pegar o copo pode realizar-se em instante anterior à realização efetiva do ato de beber e, portanto, à realização do ação temperante. Tudo isso mostra que a ação de pegar o copo, em si mesma, é neutra. Por "em si mesma", neste caso, quero dizer "do ponto de vista meramente fisiológico". Se tal ação fosse descrita unicamente como uma série de movimentos corporais orientados para a mera consecução do movimento de beber, não poderíamos avaliar seu valor moral.

Meu ponto central é o seguinte. Essas relações entre meios e fins são relevantes para compreender a divisão de trabalho entre virtude moral e phronesis?

Que a simplicidade do exemplo não nos engane. Tomemos outro, em que os meios não seriam algo tão trivial como um movimento corporal mecanicamente necessário para realizar certo propósito. Suponha-se um agente virtuoso, que acolheu o fim de ser generoso, isto é, acolheu o 
propósito de dar certa quantia moderada de bens materiais para os indivíduos que se mostrem carentes de tais bens. Renovando suas intenções a cada Ano Novo, ele planeja e escolhe por deliberação fazer, ao longo do ano, tais e tais doações para instituições de caridade e/ ou indivíduos etc. Mas, como meios que o habilitarão a honrar tais propósitos, ele planeja também certas ações de poupar seus vencimentos mensais, controlar certos gastos supérfluos, etc. E claro que, entre o fim, ser generoso, e as coisas que promovem o fim, poupar seus vencimentos, cortar gastos supérfluos etc., há a primeira ou segunda relação acima descrita. De fato, poupar vencimentos e cortar gastos supérfluos, etc., contribui para o fim de ser generoso, obviamente, mas não é suficiente para tornar alguém generoso, nem é algo que se realiza simultaneamente à efetividade da ação generosa. Além do mais, a mera ação de poupar vencimentos e cortar gastos supérfluos é neutra do ponto de vista moral e poderia perfeitamente servir como meio para o vício da avareza.

Por outro lado, para ilustrar o segundo tipo de relação entre fins e coisas que promovem os fins, tomemos o mesmo agente virtuoso, que acolheu o fim de ser generoso. Em suas intenções de Ano Novo, ele planeja e delibera fazer tais e tais doações para instituições de caridade e/ ou indivíduos ao longo do ano; digamos, uma doação mensal. É claro que cada uma dessas doações mensais, individualmente tomada, pode ser considerada como parte da realização de seu fim, que consiste em ser generoso ao longo do ano. Nesse caso, parece que os meios (as doações mensais) têm já em si mesmos um valor moral intrínseco, de modo que se poderia argumentar em favor da tese de que a phronesis teria valor moral intrínseco, sob a condição de que é a phronesis que determina o procedimento de fazer uma doação a cada mês. No entanto, mesmo nesse caso, não se prova que a phronesis tenha valor moral intrínseco. Se, dado o propósito de ser generoso por intermédio de doações regulares a instituições de caridade, cabe à phronesis determinar apenas que o melhor meio de implementar tal propósito é realizar uma doação mensal, em vez de duas doações semestrais (por exemplo), dificilmente se pode dizer que a phronesis tem valor moral intrínseco. Seu valor moral, nesse caso, ainda seria parasitário do valor moral do fim, do propósito de ser generoso. Suponha-se que algum fulano tenha o propósito de se eleger prefeito de seu município, propósito esse que ele cultiva em vista de sua mera vaidade, bem como em vista de se aproveitar do erário público para seus interesses privados. Como meio de realizar seu propósito, fulano decide parecer ser generoso e, mais particularmente, decide fazer uma significativa doação mensal para instituições de caridade de seu município. Ora, nessas circunstâncias, percebe-se que o valor moral na determinação dos meios passou para o lado oposto, em função do valor moral do fim. 
Ninguém ousaria dizer que a phronesis poderia estar subordinada à finalidade corrupta de usar do erário público para benefícios privados. Isso mostra que, já no primeiro caso, longe de termos phronesis, temos mera destreza na determinação de meios propícios para um dado fim.

Isso nos leva à opção seguinte, que consiste no terceiro tipo de relação entre fim e coisas que realizam o fim. Tomemos um exemplo envolvendo um indivíduo temperante. Vejamos como funciona a divisão de trabalho entre virtude moral e phronesis no que diz respeito à adoção de fins e coisas que promovem os fins em cada circunstância singular de ação. Quero dizer: o indivíduo temperante, em uma dada ação singular que seja considerada como exemplo de temperança, reafirma sua virtude da temperança na medida em que satisfaz três condições: (i) reafirma sua opção pelos fins moralmente corretos, (ii) reafirma sua capacidade de determinar, naquela circunstância singular, as coisas que promovem os fins moralmente corretos; (iii) realiza a ação temperante, em conformidade com fins e meios moralmente corretos ${ }^{22}$.

Pretendo focalizar a relação entre (i) e (ii), tendo em vista esclarecer de que modo entendo a terceira relação entre fins e coisas que promovem os fins. Para isso, voltarei ao exemplo da ação temperante no que concerne ao consumo de bebidas. Como sabemos, as virtudes morais, para Aristóteles, são mediedades entre o excesso e a falta ${ }^{23}$. Suponhamos que, em uma circunstância festiva, que envolve celebração com amigos etc., a virtude da temperança, consistindo em uma mediedade, não pode consistir em abstinência total de bebidas, tampouco pode consistir em beber até a embriaguez inconveniente. Mas é difícil determinar objetivamente quais são os limites que definem essa mediedade que consiste na ação temperante ${ }^{24}$. Na verdade, Aristóteles julga impossível e moralmente indesejável determinar uma regra fixa para medir a mediedade ${ }^{25}$. É pela phronesis, justamente, que se determinam esses limites, em cada caso, e a adequação de uma delimitação é circunscrita a cada caso singular. Ainda que a experiência do homem dotado de phronesis lhe permita formular certas regras gerais, certas generalizações, estas últimas jamais

\footnotetext{
22 São esses os critérios para atribuir virtude a um agente, ver Cooper, 1986, p. 63.

${ }^{23}$ Sobre a noção de mediedade na ética de Aristóteles, concordo integralmente com Urmson, 1980.

${ }^{24}$ Cf. EN II 9, 1109a 24-30, 1109b 14-23, VI 1.

25 A natureza da mediedade é tal que ela só pode ser formulada de modo universal e vago. Mais adiante, tentarei mostrar que a phronesis encontra-se em situação similar à epieikeia em EN V 1137b 11-24. Essa aproximação entre ambas confirma-se plenamente em EN VI, 1143a 19-35. A phronesis está no mesmo registro que a gnômê, a suggnômê e a sunesis: todas elas consistem em (ou envolvem) um discernimento correto do epieikos.
} 
sobrepujam a apreciação das circunstâncias e, no máximo, servem como parâmetro para a apreciação da relevância de cada circunstância singular na determinação do que vem a ser a ação correta a ser feita, do ponto de vista da virtude.

Voltemos ao exemplo da generosidade. Podemos dizer que um fulano generoso acolheu o fim (moralmente correto) de ajudar, na medida de seus recursos, aqueles que necessitam de ajuda material e a merecem. No entanto, é difícil determinam quem realmente necessita de ajuda material e quem a merece. Mais do que isso: é difícil avaliar se doar uma quantia de dinheiro ou qualquer outro aporte, em certas circunstâncias, realmente cumprirá a finalidade de ajudar quem necessita de ajuda e a merece. Suponha-se uma criança esfarrapada pedindo esmola em algum semáforo em uma grande metrópole. Por melhores que sejam as intenções do doador, e por melhores que sejam os argumentos da criança, é difícil avaliar se, por exemplo, a criança simplesmente está a ser usada por um meliante que, no final do dia, lhe tomará o dinheiro coletado e/ou a espancará se a coleta não atingir certo montante. Neste caso, doar dinheiro para a criança pode contribuir para meramente financiar um meliante, sem engendrar nenhum benefício para a criança, assim como negar o dinheiro pode contribuir para que a criança seja espancada ao fim do dia, quando o meliante vier recolher o dinheiro e encontrar uma quantia que julga insuficiente. Em que consiste, em uma circunstância como essa, a realização do fim? O fim (skopos) consiste em ajudar a criança etc. A efetiva realização do fim depende de uma série de circunstâncias cuja apreciação e avaliação escapam a qualquer regra. Essas circunstâncias não podem ser previstas de modo determinado, não podem ser captadas de modo pleno por nenhuma regra geral, ainda que uma regra geral possa ser de grande auxílio em sua apreciação ${ }^{26}$. Ora, a avaliação e apreciação dessas circunstâncias compete à phronesis. Não estou a dizer que a phronesis tenha apenas essa única e exclusiva competência. Estou a propor algo mais simples: que umas das atribuições da phronesis é apreciar e avaliar essas circunstâncias. Acrescentaria ainda que compete à phronesis (i) não apenas a tarefa puramente intelectual ${ }^{27}$ de julgar ou avaliar circunstâncias, (ii) mas também a tarefa de ordenar uma ação (cf. epiktatike 1143a 8) e levá-la a cabo, isto é realizá-la ${ }^{28}$.

${ }^{26}$ Cf. EN V, 1137b 11-24, sobre a epieikeia.

27 Ou dianoética, no sentido em que "dianoético" pode ser entendido de acordo com Ethica Nicomachea VI 2, 1039a 1 ss.

${ }^{28}$ De fato, a phronesis é definida como uma hexis praktike, 1140b 4-6, 20-21, e tomo praktike como "realizadora de ações" ou "efetiva ou eficaz no engendramento de ações". 
Pois bem: nas circunstâncias do exemplo acima, a saber, o suposto ato de generosidade envolvendo uma criança pobre etc., quais são as relações entre meios e fins? Quais são as relações entre phronesis e virtude moral. Ou melhor: se queremos captar precisamente de que modo a teoria moral de Aristóteles envolve uma divisão do trabalho entre a virtude moral e a phronesis no que concerne à eleição de fins e ao discernimento dos meios adequados, devemos recorrer a qual das três relações entre meios e fins, que acima apresentei? Das três relações que apresentei, qual delas permitiria atribuir à phronesis um valor moral intrínseco?

Ora, o valor moral intrínseco da phronesis depende, como argumentei, de sua contribuição (ainda que parcial) na determinação dos fins, isto é, nos procedimentos de apreciação que levam à adoção de fins. Mas como a phronesis poderia contribuir para determinar os fins, se o fim fosse algo já adotado de antemão pelo agente virtuoso, e adotado por ele graças a sua virtude moral, não graças à phronesis, ou adotado por ele graças à correção de seu desejo, não graças à correção de seu raciocínio sobre meios para realizar o que o desejo adotou como objeto $^{29}$ ?

Ora, no meu entender, essa questão é insolúvel no quadro das duas primeiras relações entre meios e fins. Apenas a terceira permite encontrar resposta satisfatória. A contribuição da phronesis na determinação dos fins passa a ter papel moral relevante e deixa de ser mera destreza instrumental somente se os fins, já adotados pela virtude moral do agente, são tais que, por sua natureza, necessariamente envolvem uma vagueza e requerem determinação ulterior, sem a qual seu valor moral bom se perderia por completo.

Examinemos, então, a terceira relação, à luz dos exemplos acima descritos. Como dissemos, de acordo com o terceiro tipo de relação entre meios e fins, a realização do fim consiste na realização das coisas que promovem o fim e vice-versa. Suponha-se que, avaliados todos os fatores relevantes, o agente compreenda que o fim de ser temperante, isto é, o fim de beber de acordo com a mediedade naquela singular celebração com os amigos, consiste em beber duas garrafas de vinho etc. Com "beber duas garrafas de vinho etc.", designo um ato realmente temperante: a expressão "etc." é uma abreviação para as condições que Aristóteles menciona em 1105a 28-33: efetuar um ato com conhecimento do que se faz, sob a descrição relevante do ponto de vista moral; efetuar um ato tendo-o escolhido (e não involuntariamente, por exemplo); efetuar um ato

${ }^{29}$ Cf. Kenny, 1979, p. 103. 
que foi escolhido em vista de seu valor moral intrínseco; enfim, efetuar tal ato sem conflito interno e sem vacilação a respeito da sua correção ${ }^{30}$.

Confrontemos essa situação com as três definições antes fornecidas para cada respectiva relação entre fins e meios. Ora, nessas circunstâncias, não é verdadeiro dizer que foram satisfeitas as condições que constituem a Definição (1). Toda as condições, confrontadas com nosso caso, tornam-se sentenças falsas. Vejamos: (i) beber duas garrafas de vinho etc. consiste em algo que contribui para realizar, naquela circunstância singular, o fim ser temperante; (ii) beber duas garrafas de vinho etc. não é capaz de produzir por si mesmo, isoladamente, o fim praticar a ação temperante (outros meios devem ser acrescentados), (iii) a realização ou o uso (enfim, a energeia) de beber duas garrafas de vinho etc. se dá em um instante anterior ao instante em que o fim ser temperante se realiza por completo.

É fácil entender por que a condição (ii) não é verdadeira. De fato, beber duas garrafas de vinho etc., sendo que "etc." remete ao conjunto das condições estabelecidas por Aristóteles em 1105a 28-33, é uma ação que é suficiente para produzir, em si mesma, o fim almejado, porque beber duas garrafas de vinho etc. consiste na realização desse fim naquela circunstância singular. Daí se segue facilmente que o ato de beber duas garrafas de vinho etc. não "contribui" parcialmente para a realização do fim, porque ele é a realização do fim, na circunstância singular em que o agente se encontra. Por essas razões, é também claro que o ato de beber duas garrafas de vinho etc. não foi realizado em um instante anterior ao instante em que se realizaria, finalmente, uma ação temperante.

Tampouco é verdadeiro dizer que foram satisfeitas as condições que constituem a Definição (2). De fato, são falsas todas as três asserções seguintes: (i) beber duas garrafas de vinho etc. consiste em algo que contribui para realizar, naquela circunstância, o fim ser temperante, a título de parte constitutiva do fim ser temperante; (ii) beber duas garrafas de vinho etc. não é capaz de produzir por si mesmo, isoladamente, o fim $F$ (dado que é apenas parte de ser temperante), (iii) a realização (enfim, a energeia) do ato de beber duas garrafas de vinho etc. pode dar-se em um instante anterior ao instante em que o fim ser temperante se realiza por completo.

${ }^{30}$ Interpreto a terceira condição dada por Aristóteles em 1105a 32-33 de modo não-ortodoxo. Broadie, 2002, p. 19: julga que se trata de "firm and unchanging disposition", bem similar é a opção de Taylor, 2007, p. 84: "a stable and unchangeable state of character". Esse detalhe não é importante para meus propósitos neste artigo, mas cabe ressaltar que praticar um ato "bebaiôs kai ametakinêtôs" consiste em praticar um ato virtuoso sem o conflito interno que o continente experimenta. 
Por outro lado, nas circunstâncias do meu exemplo, é verdadeiro dizer foram satisfeitas as condições que constituem a Definição (3). Vejamos:

(i) beber duas garrafas de vinho etc. consiste em algo que realiza, por sua própria realização, o fim ser temperante; (ii) beber duas garrafas de vinho etc. é um ato capaz de produzir por si mesmo, isoladamente, o fim ser temperante (dado que realizar $m$ consiste em realizar $F$ ), (iii) a realização (enfim, a energeia) do ato de beber duas garrafas de vinho etc. se dá simultaneamente à realização do fim ser temperante.

Enfim, há uma identificação circunstancial entre fim e meio. Quero dizer o seguinte. Naquela circunstância singular (mas não necessariamente em nenhuma outra), o fim, que fora descrito de modo vago, ser temperante etc., torna-se idêntico ao meio, que é plenamente determinado porque envolve singulares. Desse modo, se o fim tem um valor moral intrínseco, pode-se entender por que a determinação dos meios não é moralmente neutra, mas tem também valor moral. Os meios nada mais são que a determinação plena do fim em uma dada circunstância singular ${ }^{31}$.

Ocorre com a relação entre fins e meios algo similar à relação entre a lei e o epieikes (1137b 11-27). Toda lei deve ser universal, pela sua própria natureza de lei, mas, devido à natureza dos fatos sobre os quais a lei legisla, é impossível considerar todos os casos corretamente do ponto de vista universal. A universalidade da lei é incapaz de prever a multiplicidade de casos singulares que podem ocorrer sob seu domínio. Não se trata de uma falha da lei em si mesma, nem de uma falha de um suposto legislador medíocre: é a própria natureza das ações que não permite à lei a precisão que seria desejada. Por isso, quando ocorre um caso que não estava previsto na universalidade da lei ("sumbêi d' epi toutou para to katholou", 1137b 20-21), deve-se corrigir a omissão ou a falha da lei, observando, face ao caso singular em questão, aquilo que o legislador determinaria, se deparasse com tal caso.

Não preciso desenvolver até as últimas conseqüências a noção aristotélica de "epieikes". Basta-me dizer que a relação entre lei universal

31 Isso permite compreender por que uma ação que conta como exemplo de ação virtuosa pode ser descrita como uma ação que foi feita "em vista de si mesma" (cf. 1144 19-20) ou "escolhida por si mesma" (1105a 32). A ação foi escolhida e foi feita "em vista do fim", isto é, em vista do propósito de realizar a virtude moral. No entanto, dado que há, entre o propósito vago adotado pelo caráter do agente virtuoso e a realização da ação virtuosa (que é sempre singular), uma identificação circunstancial, pode-se descrever a ação (com a plena determinação dos fatores singulares) como uma especificação do fim (tal como descrito pelo agente em seu propósito vago), de modo que "fazer a ação em vista do fim" equivale a "fazer a ação em vista dela mesma". 
e caso singular que exige a intervenção da epieikeia é similar à relação entre o fim adotado como propósito (graças à correção do desejo pela virtude moral) e os meios que realizam o fim (determinados pela correção do logos que caracteriza a phronesis). O fim adotado pelo agente moral, considerado abstratamente, é apenas um desígnio vago, se não for determinado em confronto com os fatores relevantes que cada circunstância singular apresenta. A vagueza e generalidade dos propósitos morais não é uma falha do agente moral ${ }^{32}$, mas é algo inevitável que decorre da própria "matéria" na qual se aplicam as virtudes morais: é algo que decorre da própria natureza das ações e das circunstâncias que as envolvem $^{33}$. Pode-se discutir a natureza do caso que não estava previsto na universalidade da lei ("sumbêi d' epi toutou para to katholou", 1137b 20-21). Pode-se julgar que a lei, mesmo sendo universal, delimita claramente um domínio dentro do qual os casos singulares ocorrem, e ocorrem variadamente, sem que seja possível prever suas especificidades. Poder-se-ia julgar que o caso que não estava previsto na universalidade da lei seria um caso que se situa fora desse domínio, ou seja, um caso que se situa para além dos limites circunscritos pela generalidade da lei. Não pretendo discutir qual seria a compreensão correta desse problema na teoria aristotélica da epieikeia, mas, quanto ao meu ponto, que diz respeito à relação entre fins e meios na distribuição de encargos entre virtude moral e phronesis, diria que a compreensão acima sugerida não é correta. Quero dizer o seguinte: o caso singular que não estava previsto na universalidade do fim adotado como propósito pela virtude moral não seria bem descrito como um caso que cai para além do domínio circunscrito por tal propósito. $\mathrm{O}$ caso que não estava previsto na universalidade do propósito moral é um caso que, situado nos confins já previstos pela própria formulação vaga do propósito, requer cômputo detalhado dos fatores relevantes devido à própria natureza das ações e das circunstâncias em que elas ocorrem. O que quero dizer com "requer" é o seguinte: o cômputo detalhado dos fatores relevantes em cada circunstância singular em que se aplica um propósito moral é uma condição necessária para a

${ }^{32}$ Mas torna-se uma falha do agente, se não receber adequadamente determinações ulteriores, face aos fatores relevantes em cada circunstância singular. Nesse caso, quando não há determinação ulterior adequada dos propósitos morais, não mais se pode que o agente é virtuoso.

${ }^{33}$ Não surpreende, portanto, que Aristóteles ressalte o parentesco da phronesis com uma série de outras disposições (sunesis, eusunesia, gnômê, suggnômê) cuja característica comum é exatamente saber discernir o que é "epieikes": ver EN VI 11-12, 1142 b 35 ss., especialmente 1143a 19-35. 
realização da ação moral, bem como uma condição necessária para determinar seu caráter moral. Sem esse cômputo, o propósito moral permanece como mero protocolo provisório, ou uma nota promissória não honrada. Um propósito moral que permanece vago em cada ação singular, por não considerar os fatores relevantes em cada circunstância singular, seria no máximo apropriado à "virtude natural", a qual talvez seja chamada de virtude apenas por homonímia, em razão de certas semelhanças ${ }^{34}$.

Podemos, então, compreender por que não há nenhum conflito entre as seguintes afirmações de Aristóteles: a) a virtude é uma hexis prohairetike (1106b 36); b) a prohairesis diz respeito a ta pros ta tele (1111b 26-27) (independentemente de como se toma mallon) ${ }^{35}$; c) a virtude responde pela correção dos fins ao passo que a phronesis (que não é uma hexis prohairetike) diz respeito à correção das coisas pros ta tele.

Podemos, nessa perspectiva, compreender o início de Ethica Nicomachea VI de modo bem esclarecedor quanto à divisão de trabalho entre virtude moral e phronesis. Termino este artigo com uma paráfrase que, no meu entender, capta o que Aristóteles quer dizer no capítulo 1 do referido livro:

"Dado que falávamos que é preciso adotar a mediedade, em vez do excesso ou da falta, e que a mediedade é tal como a apreciação correta determina, elucidemos esse ponto. Em todas as disposições mencionadas (isto é, as disposições que são virtudes morais), bem como em outras disposições, há certo fim (descrito, porém, de modo inevitavelmente vago), e é observando esse fim (tendo-o como parâmetro) que quem tem uma apreciação correta estica ou relaxa. Ou seja, há certa determinação ou delimitação das mediedades (que são intermediárias entre excesso e

${ }^{34}$ De fato, a virtude natural, sem o nous da phronesis, é prejudicial (1144b 9) e não satisfaz a definição geral de virtude dada em II 6, 1106a 15-21, nem a definição de virtude moral dada em II 6, 1106b 36-1107a 2. De fato, a chamada "virtude natural" não é algo "que faz que seu possuidor seja bom e lhe permite um bom desempenho de sua função própria", pois ela pode ser prejudicial e envolve um mau desempenho no exercício da razão. De modo similar, a "virtude natural" não é uma "disposição baseada em escolhas, consistindo na mediedade para nós, determinada pela razão e tal como o phronimos a determinaria", pois lhe falta justamente a consideração correta das circunstâncias singulares, que é tarefa da phronesis.

35 Supondo-se que o mesmo "mallon" explicitado em 1111b 25 está subentendido na linha seguinte, em 1111b 26, pode-se interpretá-lo de dois modos: como se introduzisse uma mera gradação ("a prohairesis é mais dos meios do que dos fins", o que não exclui que ela tenha relação com os fins), ou como se introduzisse uma restrição excludente ("a prohairesis é antes dos meios, não dos fins"). Mas a interpretação que propus neste artigo funciona sob qualquer uma das opções acima. 
falta), as quais se realizam plenamente de acordo com a apreciação correta. Ora, falar desse modo (em termos de fins e parâmetros) é verdadeiro, mas não é claro (é vago): de fato, também em outros terrenos em que há certo conhecimento, é verdadeiro dizer, por exemplo, que não se deve fazer exercícios nem em maior nem em menor quantidade, senão em quantidade média, isto é, como a apreciação correta diz. No entanto, quem souber apenas isso não saberá nada mais, por exemplo, não saberá quais coisas deve aplicar ao corpo, se souber que deve aplicar 'aquilo que a medicina ordena' e/ou 'aquilo que ordena quem conhece a arte da medicina'. Por isso, também no que respeita às disposições da alma, é preciso não apenas que isso (touto $=$ que se deve adotar a mediedade, tal como a apreciação correta ordena) seja verdadeiro; é preciso também que isso receba ulterior determinação: um agente deve delimitar em que consiste essa apreciação correta (orthos logos = phronesis), ou melhor, ele deve saber qual é a determinação ou delimitação (horos) que essa apreciação correta, mas vaga, deve receber em uma circunstância singular" (1138b 18-34).

\section{REFERÊNCIAS BIBLIOGRÁFICAS}

ANGIONI, L. (2009). Aristóteles - Física I-II. Campinas: Editora da Unicamp. BROADIE, S., \& ROWE, C. (2002). Aristotle: Nicomachean Ethics. Oxford: Oxford University Press.

COOPER, J. (1986). Reason and Human Good in Aristotle, Indianapolis: Hackett.

COOPER, J. (1999). "Reason, Virtue and Moral Value", in Reason ans Emotion, Princeton: Princeton University Press.

KENNY, A. (1979). Aristotle's Theory of the Will, London: Duckworth.

KRAUT, R. (1989). Aristotle on the Human Good, Princeton: Princeton University Press.

IRWIN, T. (1999). Aristotle: Nicomachean Ethics, Indianapolis: Hackett.

REEVE, C. D. C. (1992). Practices of Reason, Oxford: Oxford University Press. REEVE, C. D. C. (2008). Nicomachean Ethics - Book VI. Mimeo.

TAYLOR. C. C. W. (2007). Aristotle: Nicomachean Ethics, Books II-IV, Oxford: Oxford University Press (Clarendon Aristotle Series).

URMSON. J. (1980). "Aristotle's Doctrine of the Mean", in Rorty, A.O. (ed.), Essays on Aristotle's Ethics, Berkeley: University of California Press, pp. 157-170. 